latter term is understood in the sense used by Cassirer in his Philosophy of Symbolic Forms and used also by such prehistorians as Frankfort. The connexion of the mass media advertising and new culture heroes and heroines with contemporary myth is outlined.

Consideration of these social realities of our time must involve a criticism of one of the fundamental aspects of sociological theory: this is the unstated idea that some sort of equilibrium system or balance sheet formulation can be used in sociological study of religion and ideology.
Rather is it suggested that the logical incompatibility of ideological elements is no barrier to their simultaneous growth and development in social structures, although in certain specific circumstances such incompatibilities may emerge and be of real importance in precipitating radical social change. Finally, an attempt is made to relate the account of contemporary secular religion and the criticism of sociological theory that this account entails to the general sociology of religion current among contemporary sociologists.

\title{
SCIENTIFIC UNDERSTANDING AND THE CHIEF END OF MAN
}

$\mathrm{S}$ INCE the collision between T. H. Huxley and Bishop Wilberforce at the British Association meeting in Oxford in 1860, further radical advances in scientific understanding have taken place. The enormous industrial productivity of a modern State is based on Faraday's studies of electromagnetism, the work of Joseph Black on latent heat underlying the perfection of the steam engine, chemical researches into large molecules leading to the present plastics industry and, more recently, on a combination of investigations of solid-state physics culminating in the development of transistors combined with Babbage's conception of a general-purpose digital computer. Dr. Magnus Pyke, in his presidential address to Section $\mathrm{X}$ (General), considers that all this and more is bringing about a state of affairs when earning a living can no longer be considered a major goal of human endeavour.

In the past hundred years, advances in chemistry and biology have changed men's ideas of the nature of famine and pestilence. The yields of arable crops have been consistently increased by the use of chemical fertilizers and, above all, by the breeding of improved strains of both plants and animals. Statistical evidence has been presented by Mayer ${ }^{1}$ suggesting that the proportional increase thus achieved in world food supplies during the past two decades has been greater than the parallel increase in population and that this is part of a general trend that has been proceeding since the $1850 \mathrm{~s}$. The effect of scientific advance on medicine has been even more profound. Understanding of the nature of infectious diseases originated with Pasteur; aseptic surgery, anaes- thetics and immunology are further examples of new knowledge; and chemotherapeutic agents and antibiotics were only developed by scientists of the present generation.

Great though the effect of scientific understanding has been on man's material condition, its influence on his thought and belief has been more profound still. Earthquakes and epidemics can no longer be feared irrationally as capricious retribution for public sins, nor need individual illnesses any longer be attributed to the evil eye. The universe has become a rational and, in many respects, a controllable place. The nature of the intellectual process which constitutes science which has brought this about can be seen to be an amalgam of observation, reason and imagination constantly refined by repeated reference back to Nature. Science can thus in many respects be compared with poetry as a way of finding truth. The present intellectual schism is between those who base their behaviour on dogma and those who put their faith in the belief that the exercise of reason and imagination in search of truth is the basic human goal.

MacKay ${ }^{2}$ has already pointed out that it was concern for truth which begot science, not science which begot concern for the truth. It is argued that to continue to pursue the truth, which is, in its essentials, the pursuit of a moral goal, by means which have already successfully brought material wealth, food, healing and understanding of Nature and of man himself, is a worthy end for human endeavour.

${ }^{1}$ Mayer, J., Nutrition Rev., 22, 353 (1964).

${ }^{2}$ MacKay, D. M., in Man and his Future, edit. by Wolstenholme, G., 372 (Churchill, London, 1963).

\section{PRESIDENT FOR 1966 OF THE BRITISH ASSOCIATION}

\section{SIR JOSEPH HUTCHINSON, C.M.G., F.R.S.}

GIR JOSEPH HUTCHINSON, Draper's professor in the University of Cambridge, has been elected president for 1966 of the British Association for the Advancement of Science. Sir Joseph will deliver his presidential address at the next annual meeting in Nottingham.

Sir Joseph succeeded Sir Frank Engledow in the chair at Cambridge in 1957, and to repeat that which appeared in Nature on that occasion should indicate sufficiently that the British Association has made an excellent choice in the successor to Sir Cyril Hinshelwood as president.

Sir Joseph was born in 1902 and was educated at Ackworth and Bootham Schools, and at St. John's College, Cambridge. After graduation, he took a postgraduate course at the Imperial College of Tropical A.griculture, Trinidad, and then joined the Empire Cotton Growing Corporation's Cotton Research Station as assistant geneticist in 1926, the year in which the Station was established. He soon proved himself a worker of notable quality, and began a long series of researches on the genetics and taxonomy of the cotton plant which ultimately established him as one of the world's leading authorities. After seven years in Trinidad he gained further valuable experience in India, where he was from 1933 until 1937 geneticist and botanist at the Indore Institute of Plant Industry. Returning to Trinidad as chief geneticist at the Cotton Research Station, he continued, with the aid of his colleagues, Dr. R. A. Silow and Dr. (now Prof.) S. G. Stephens, the elaborate series of genetical and evolutionary studies on the genus Gossypium which culminated in a joint work entitled The Evolution of Gossypium and the Differentiation of the Cultivated Cottons. This book was highly praised and takes its place among the classics of biology as perhaps one of the most comprehensive studies of the evolutionary history of a single genus ever carried out.

With the shutting down of the Trinidad Station in 1949, Sir Joseph went to Uganda as the first director of the Empire Cotton Growing Corporation's Cotton Research Station at Namulonge. Elected to the Royal Society in 1951, he was knighted in 1956. Since 1953 he has served as chairman of the Council of Makerere College, the University College of East Africa. 